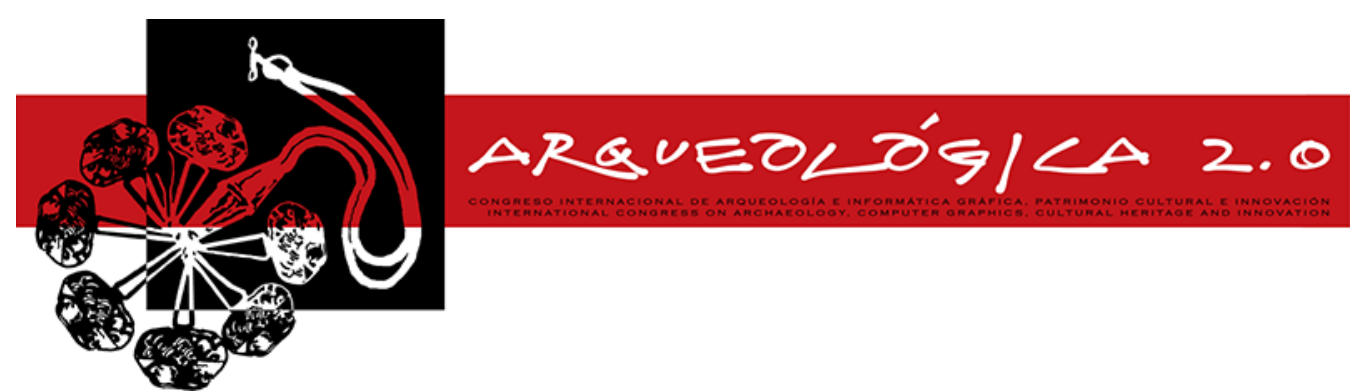

Proceedings of the $8^{\text {th }}$ International Congress on Archaeology, Computer Graphics, Cultural Heritage and Innovation 'ARQUEOLÓGICA 2.0'

in Valencia (Spain), Sept. $5-7,2016$

DOI: http://dx.doi.org/10.4995/arqueologica8.2016.2993

\title{
DOCUMENTACION DIGITAL APLICADA A LA VILLA ROMANA DE SANT GREGORI (BURRIANA, ESPAÑA)
}

\author{
DIGITAL DOCUMENTATION APPLIED TO THE ROMAN VILLA SANT GREGORI (BURRIANA, SPAIN) \\ José Manuel Melchor ${ }^{\mathrm{a},{ }^{*},}$, Josep Benedito ${ }^{\mathrm{b}}$, Juan José Ferrer ${ }^{\mathrm{a}}$, José Ricart ${ }^{\mathrm{c}}$, Rafael Ayora ${ }^{\mathrm{c}}$ \\ ${ }^{a}$ Departament d'Història, Geografia i Art, Universitat Jaume I, Av. Sos Baynat s/n, 12071 Castellón, España. melchor@uji.es; \\ jerrer@uji.es \\ ${ }^{\mathrm{b}}$ Departament d'Història de l'Antiguitat i de la Cultura Escrita, Universitat de València, Av. Blasco Ibáñez 28, 46010 Valencia, España. \\ Josep.Benedito@uv.es \\ 'SIGMA SCAN SC, San Blas 66, planta 3, pta. 1, 12500 Vinaròs, Castellón, España. info@sigma-scan.es
}

\begin{abstract}
:
In this paper we aim at presenting the digitalization process done on the archaeological site at San Gregori a villa a mare from the Early Roman Empire found in Burriana, a Mediterranean coastal village of Spain. The archaeological work is part of a joint research project carried out by Universitat Jaume I in Castellón and the Archaeological Museum of Burriana. To date, the residential part of the villa in the northeast corner of the settlement has been excavated; this area is situated about 100 meters from the waterfront. The villa has been dated around the change of Era and IV c. A. D.; however, some Roman republican and Iberian materials have also been registered. The last phase of the work consisted on the development of a $3 \mathrm{D}$ laser scanning to complete the graphical work for the archaeological documentation of the site.
\end{abstract}

Key words: Roman villa, digital archaeology, Burriana, scanner, documentation, planimetry

\section{Resumen:}

En este artículo se presentan los trabajos de digitalización realizados sobre los restos arqueológicos del yacimiento de Sant Gregori, una villa marítima de época romana alto imperial situada en la costa de Burriana. Los trabajos arqueológicos forman parte de un proyecto de investigación desarrollado por la Universitat Jaume I de Castellón y el Museo de Burriana. Hasta la fecha se ha excavado la parte residencial de la villa, localizada en el extremo noreste del asentamiento, aproximadamente a $100 \mathrm{~m}$ de la línea de costa. La villa se ha datado entre el cambio de Era y el siglo IV d. C., aunque también se han registrado materiales de época romano republicana e ibérica. La última fase de los trabajos ha consistido en realizar un escáner láser 3D, que completa los trabajos gráficos de documentación del yacimiento.

Palabras clave: villa romana, arqueología digital, Burriana, laser escáner, documentación, planimetría.

\section{El yacimiento}

Los restos romanos de Sant Gregori fueron descubiertos por N. Mesado en la década de 1970 (Verdegal et al. 1990), quien llevó a cabo dos efímeras campañas de excavación. La primera intervención se realizó en 1978 , un sondeo en la parcela situada en primera línea de playa, en el que se salieron a la luz algunos muros, fragmentos de mármol y cerámica. En 1987 se efectuó una nueva campaña en la que se descubrieron varias habitaciones de planta cuadrangular y fragmentos de revestimiento de mortero con pintura mural, que indican que algunas paredes debieron estar pintadas. Los pavimentos eran de mortero de cal y ladrillos. También se registró una gran cantidad de teselas de color blanco y negro, lo que sugiere que en el yacimiento debía existir un mosaico bicromo. De estas primeras intervenciones sólo se conservan en el Museo Arqueológico memorias incompletas y algunas fotografías, tampoco se realizó ningún trabajo de clasificación de los hallazgos.

En el año 2003 se llevó a cabo una prospección arqueológica en los terrenos de la villa. Años después, en el 2009 se realizó una prospección electromagnética

*Corresponding Author: Josep Benedito, Josep.Benedito@uv.es 
que reveló importantes diferencias en la consistencia del subsuelo. El sistema de georradar confirmó la existencia de una apreciable zona de contacto entre la arena de aportación marina y una serie de estructuras y vertidos romanos. Como complemento de esta intervención se llevó a cabo en el año 2010 una campaña de sondeos arqueológicos con el objeto de delimitar el perímetro de la villa.

Desde el año 2011 se han llevado a cabo cinco campañas anuales de excavación arqueológica a cargo del Museo Arqueológico Municipal de Burriana en colaboración con la Universitat Jaume I de Castellón. Desde entonces, los trabajos han permitido sacar a la luz un conjunto de estructuras arquitectónicas muy interesantes de la única villa costera de época romana excavada hasta la fecha en la provincia de Castellón.

Sant Gregori se halla en la costa norte de Burriana, una franja litoral baja, rectilínea y estrecha, formada por una sucesión de abanicos aluviales (Fig. 1). En época romana era un área lagunar junto a la desembocadura del río Anna y el antiguo barranc de l'Hospital. La villa se ha datado entre el cambio de Era y el siglo IV aunque tiene lugar una notable obra de reforma entre el siglo II y III. El buen estado de conservación de los pavimentos no permitió continuar la excavación, pues hubiera supuesto la destrucción de estos restos (Fig. 2). Con todo, en época Moderna algunos sectores de la pars urbana de la villa sufrieron la excavación de zanjas y fosas con el objeto de extraer material constructivo, que tal vez trasladarían a las salinas medievales, que sabemos que fueron rehabilitadas entre 1570 y 1580 . En estos rellenos se registraron importaciones de cerámica itálica y cerámica campaniense A, B e ibérica. Estos materiales podrían sugerir que el lugar ya fue ocupado entre los siglos III y I a. C., en un momento anterior a la construcción de la villa. Por otro lado, en el último de los niveles de la excavación, que se ha hallado en contacto con la capa freática, se encontró cerámica de la Edad del Bronce y del Hierro antiguo, así como algún fragmento de ática. Sin embargo, estas cerámicas no se asocian a niveles estratigráficos claros y solo los futuros trabajos permitirán aclarar qué hacen ahí estos artefactos (Melchor et al. 2014).

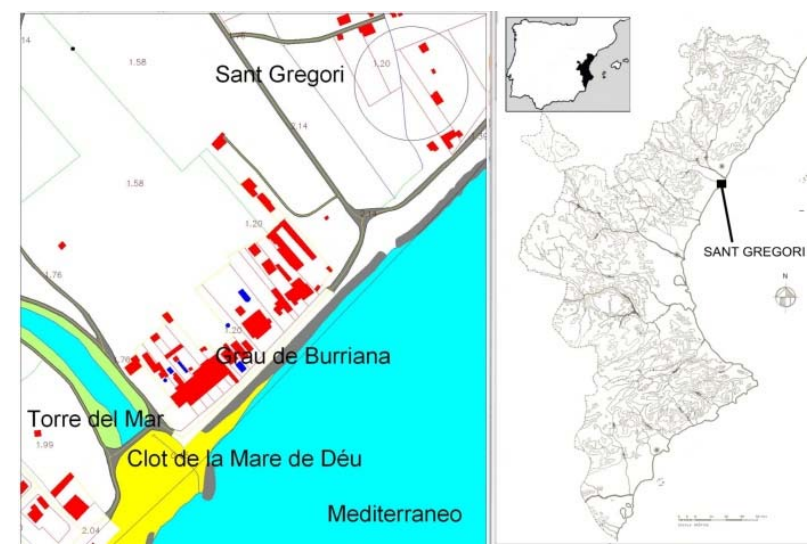

Figura 1: Plano de situación de la villa romana de Sant Gregori.

Los hallazgos más relevantes realizados hasta el momento a nivel arquitectónico, corresponden a un peristilo orientado de norte a sur datado en el siglo I, que constaría de un espacio ajardinado alrededor de un impluvium rectangular, de 9,80 por $1,75 \mathrm{~m}$ y cimientos de $95 \mathrm{~cm}$ de ancho, revestido de opus signinum y aristas acabadas con juntas de cuarto de bocel, además cuenta con una tubería de plomo, a través de la cual el agua se decantaría probablemente hacia el hortus de la villa. Este espacio ajardinado se amortizó posteriormente con una serie de pavimentos de opus caementicium (Ferrer et al. 2013) y a un monumento funerario, probablemente un columbario familiar, de 4,25 $\mathrm{m}$ de lado, situado en una esquina exterior del peristilo, la estructura es de morfología cuadrangular y pavimento de cantos rodados. En los rellenos de colmatación se encontraron fragmentos de placas y molduras de mármol, que pudieron formar parte de su decoración arquitectónica.

Este espacio fue profundamente transformado en el siglo II para crear un área de almacenes, pues se recuperaron dos dolia (Ferrer et al. 2014) registrándose en líneas generales una disminución de la riqueza del enclave.

Respecto a los hallazgos muebles, se han recuperado sigillatas itálicas, hispánicas y sudgálicas, engobe rojo pompeyano y paredes finas, que se fechan desde finales del siglo I a. C. y durante todo el siglo I d. C. En el Alto Imperio la villa muestra una notable riqueza: mármoles, vidrio, lapis specularis y un amplio muestrario de fragmentos de pintura mural decorados, indicios de un mosaico en opus tesselatum y un opus sectile.

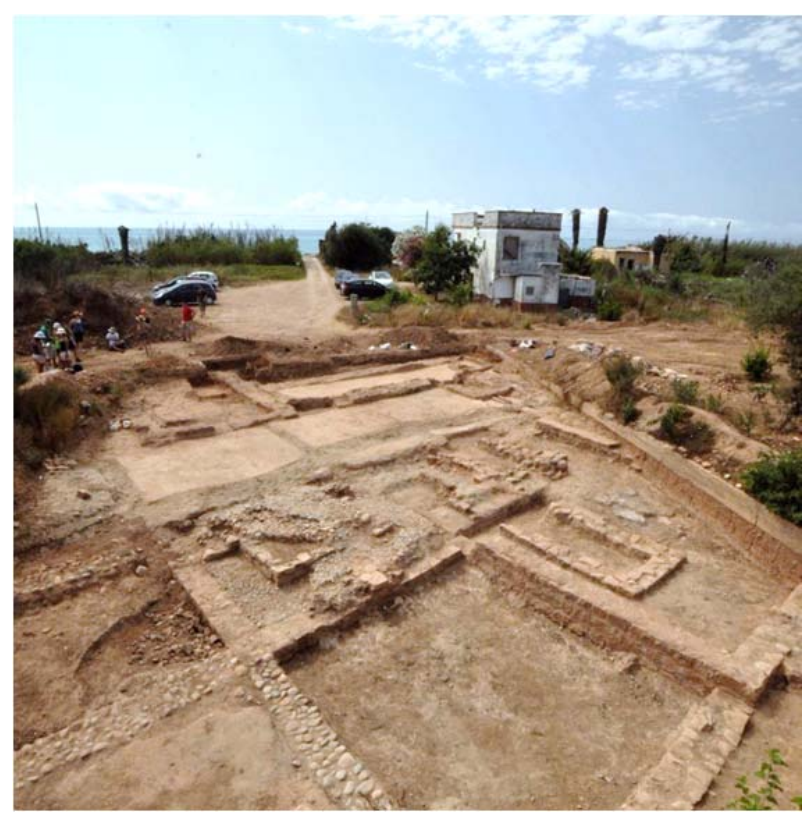

Figura 2: Proceso de excavación de la villa.

\section{La villa y su contexto histórico}

Sant Gregori podría tratarse de un tipo de villa marítima polifuncional, similar a otras localizadas en la costa peninsular, sin embargo averiguar las funciones que podría haber ejercido este asentamiento es una cuestión que todavía se nos escapa. Por un lado, el fundus de estas instalaciones se hallaría en medio de una zona de marjales, como ya citamos anteriormente, por lo que su explotación agrícola no sería fácil. Debemos examinar la relación que tiene Sant Gregori con los yacimientos del Marjalet (Melchor 2013) y del Palau (Melchor y 
Benedito 2000), localizados a 1,7 y $3,5 \quad \mathrm{~km}$ respectivamente.

Otra cuestión está relacionada con el límite norte del territorium saguntino que se ha situado en el río Millars. Este enclave es el último yacimiento costero excavado que se localiza al sur del citado río, por lo que su emplazamiento debería tener cierta relevancia (Ferrer et al. 2013).

Las evidencias materiales sugieren que se trata de un enclave utilizado para servir de punto de apoyo al transporte de mercancías y controlar el paso de una vía (Fig. 3). Sant Gregori encajaría así en un panorama rural en el que el sistema de uillae e incluso de uici, serviría para vigilar caminos y campos, utilizarse como almacenes y ocasionalmente servir de alojamiento (Ferrer et al. 2013).

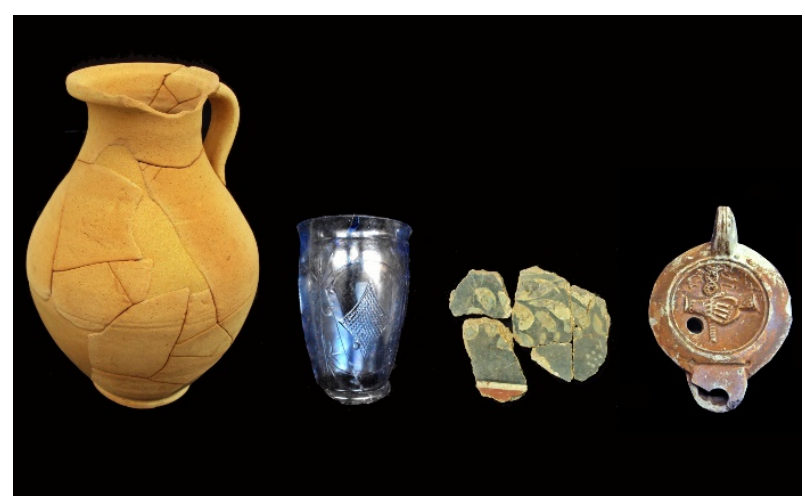

Figura 3: Materiales arqueológicos de la villa de Sant Gregori.

\section{El proceso de documentación digital de la villa}

El siguiente paso en la ejecución del proyecto de investigación fue realizar un escaneado mediante láser de todo el yacimiento. Para ello se ha contado con la colaboración de SIGMA SCAN, empresa ubicada en la provincia de Castellón especialista en el campo de la topografía, escaneado láser terrestre y geomática. Su misión ha sido llevar a cabo los trabajos de escaneado y posterior procesado de los datos para dotar al proyecto de una nueva dimensión en la documentación del yacimiento arqueológico.

Hasta la fecha, los yacimientos se documentaban a través de levantamientos topográficos, croquizados de detalle y fotografías. Gracias al desarrollo tecnológico experimentado en los últimos años en el campo de los equipos topográficos y la informática, se han incorporado a estas técnicas clásicas de registro los escaneados láser 3D, modelos virtuales y demás disciplinas que permiten el tratamiento de los datos en sus tres dimensiones.

\subsection{Descripción de los medios técnicos}

El gran avance de la tecnología de escaneado láser, nos permite aprovechar su inmenso potencial en el campo de la documentación arqueológica y conservación del patrimonio, entre otros ámbitos. Con la tecnología láser escáner 3D, se pueden generar imágenes tridimensionales de geometría y entornos complejos. Es una metodología de captura masiva de datos mediante la que se obtienen grandes nubes de millones de puntos que reflejan de manera fidedigna los objetos y entornos deseados con la posibilidad de dotar a dichos puntos de niveles de intensidad y colores reales, lo que nos lleva a alcanzar una representación fotorrealista.

Es una metodología emergente y en constante evolución. Existen principalmente dos clases de técnicas de medición en el campo del láser escáner: 1) Tiempo de vuelo (TOF - Time of Flight) que se basa en la medición del tiempo de transmisión del láser en su trayectoria de ida y vuelta desde el emisor-receptor hasta el objeto escaneado. 2) Diferencia de Fase (Phase Shift) basado en el cálculo de la diferencia de fase entre el láser emitido y el recibido.

Ambas tecnologías presentan valores de precisión similares (3-4 mm), siendo la velocidad de toma datos mucho mayor la de los equipos de diferencia de fase (1 millón puntos/seg) frente a los de tiempo de vuelo (100.000 puntos/seg). Todas estas prestaciones son mejoradas continuamente por los distintos fabricantes que dotan a sus equipos de mayor velocidad, superior alcance y mejor precisión a un ritmo formidable.

Prácticamente todos los modelos están provistos de cámaras digitales que permiten realizar fotografías del entorno escaneado $y$, de este modo, dotar a la infinidad de puntos obtenidos, del color capturado en las imágenes. Ello permite obtener una nube de puntos coloreada con una mejor representación de realidad.

Un factor fundamental en esta tecnología es la gestión de los datos en gabinete, ya que es esta tarea la que requiere de mayor especialización por parte del equipo técnico y supone cerca de un $80 \%$ del tiempo invertido en el proyecto. Los programas informáticos van avanzando en la automatización de procesos, como el registro de las distintas estaciones y la limpieza de las nubes de puntos brutas, aunque siempre es de suma importancia la experiencia y buen hacer del técnico para obtener unos resultados óptimos.

En nuestro caso, se optó por un modelo de escáner de 'tiempo de vuelo', en concreto se utilizó el escáner C10 de la casa Leica. Un instrumento que nos permitía llevar a cabo el registro de campo con una calidad y tiempos de captación de datos óptima para las características que presenta nuestro yacimiento.

El proyecto ejecutado en Sant Gregori se ha gestionado con el software 'Cyclone', también de la casa Leica, con el que se han realizado las tareas de registro de estacionamientos, limpieza de nubes de puntos, digitalización de elementos principales y creación de material divulgativo (videos, fotogramas, etc.). Todo ello con el objetivo de obtener la mejor calidad posible en la documentación técnica que sería utilizada en el estudio arqueológico.

\subsection{Trabajos de escaneado y tratamiento de los resultados}

Los trabajos de escaneado consisten principalmente es la toma de datos desde diferentes puntos de manera que se cubran con suficiente densidad y calidad de puntos todo el ámbito de estudio. 


\subsubsection{Planificación}

El primer paso en los trabajos de escaneado ha sido llevar a cabo una exhaustiva programación de las estaciones que posteriormente se realizarían en campo. Estos trabajos de planificación son de gran importancia para minimizar los futuros problemas en la gestión de las nubes de puntos escaneadas. En el caso de realizar insuficientes escaneados, tenemos el inconveniente de la falta de información, siendo habitual presentar espacios de sombra en los que, al no disponer de las necesarias referencias para generar el modelo, no se podrán analizar sus características. Si nos encontramos en la circunstancia contraria, con la presencia de excesiva cantidad de datos registrados, nos veremos con el obstáculo de gestión de los mismos, algo que, debido a la gran dimensión de los archivos generados con esta técnica, puede ser un gran problema para alcanzar los objetivos del proyecto, ya que esta situación puede dificultar mucho la tarea de limpieza inicial para eliminar el ruido generado en cada escaneado.

Antes de iniciar cada proceso de escaneado, se tomaron una serie de dianas distribuidas a lo largo del ámbito de estudio con el objetivo de asegurar y facilitar el registro de los diferentes estacionamientos (Fig. 4). La ubicación de cada una de estas dianas también se ha tenido en cuenta en el proceso de planificación que estudia el posicionamiento de las estaciones. Siendo suficientes dos dianas comunes entre escaneados sucesivos para el registro automático, la situación ideal sería aquella en la que nos encontráramos tres o más dianas.

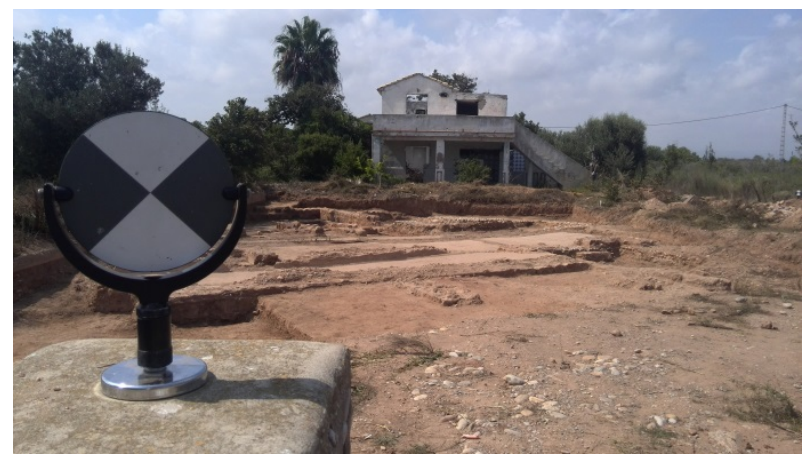

Figura 4: Diana de registro y vista general del yacimiento.

\subsubsection{Escaneado}

Por último, se llevaron a cabo 16 escaneados, obteniendo tras su procesado un modelo cercano a los 112 millones de puntos (Fig. 5).

También se realizaron fotografías desde la cámara digital propia del instrumento. Podremos generar así las nubes de puntos con el color verdadero procedente de dichas fotografías, creando de este modo visuales con una alta percepción de la realidad.

Como complemento a las labores de escaneado, se realizó el levantamiento por medio de observaciones GPS-GNSS de puntos significativos del ámbito de actuación que nos permitieron georreferenciar el trabajo.

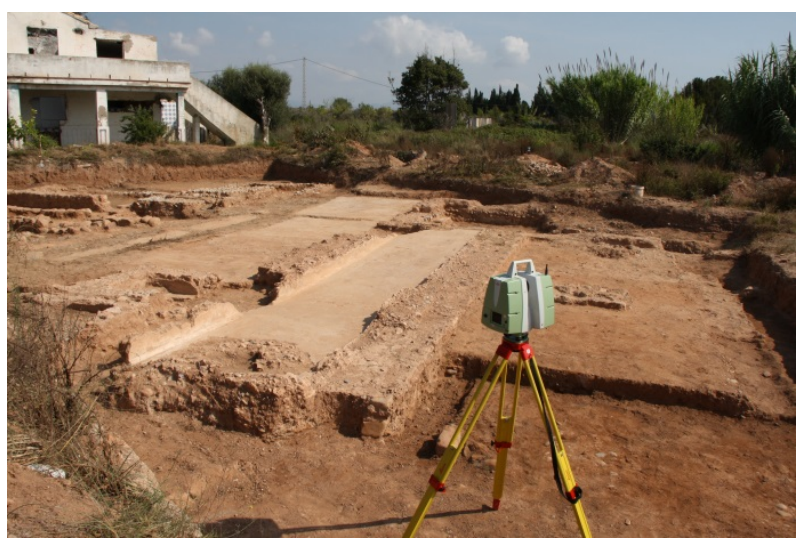

Figura 5: Vista general del yacimiento y el escáner C10 Leica.

\subsubsection{Procesado}

El primero de los trabajos de gabinete fue el registro automático de los distintos escaneados, utilizando para ello la composición de los pares de dianas comunes entre estaciones. Desechadas de la ecuación de ajuste las dos combinaciones con mayor residuo, se alcanza la solución de ensamble definitivo en la que los residuales obtenidos se encuentran dentro de los parámetros establecidos con anterioridad al inicio del proyecto. Los resultados ofrecieron residuales óptimos, con valores de entre $1-3 \mathrm{~mm}$ y valor máximo de $4 \mathrm{~mm}$.

Seguidamente comenzó el arduo trabajo de limpieza de las nubes de puntos de cada uno de los escaneados (Fig. 6). Se trata del proceso más delicado y minuciosos del proyecto en el que se analiza el conjunto de nubes de manera pormenorizada, eliminando el ruido y elementos registrados ajenos al estudio. Cuanto más cuidado y riguroso sea este proceso, mayor será la calidad de los datos presentados en el resultado final.

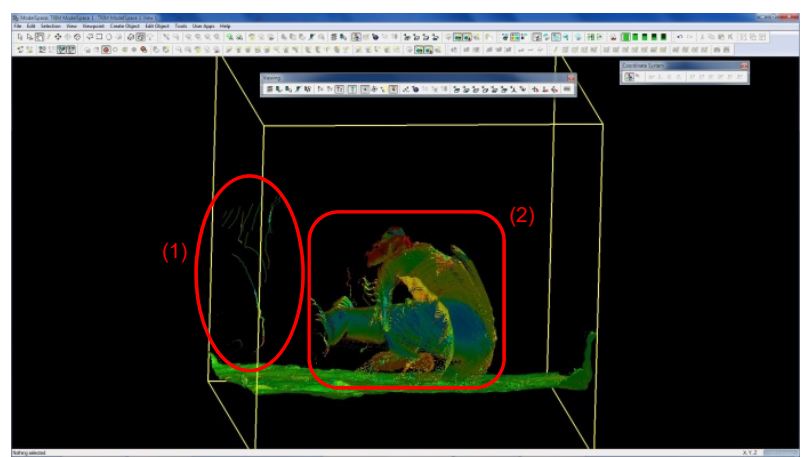

Figura 6: Ejemplo del proceso de limpieza de la nube de puntos.

En la Figura 6 puede observarse un ejemplo muy representativo del proceso de limpieza. En él se puede distinguir el ruido generado por la interrupción del escaneado, como puede ser el paso de alguna persona u objeto por el campo de exploración del escáner (1) y también el registro de elementos que no forman parte del ámbito de estudio, como en este caso es la figura de un colaborador en los trabajos de excavación (2).

Finalmente se digitalizaron los elementos principales de manera que nos permitiera obtener el plano de planta a escala del yacimiento. Con la clasificación de cada uno de estos elementos, se logra tener un mapa cronológico de las estructuras. 
Al mismo tiempo, se elaboraron una serie de los perfiles más representativos que nos permitían tener una visión en alzado.

\subsubsection{Resultados}

La base de los resultados obtenidos tras la gestión de la información escaneada es la nube de puntos procesada (Fig. 7)

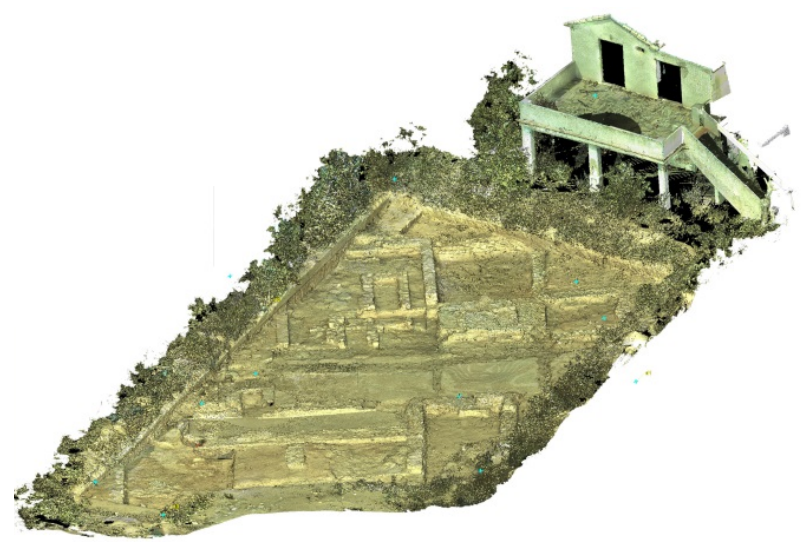

Figura 7: Vista general de la nube de puntos procesada.

La documentación final se divide en varios grupos: planos, ortofotos, fotogramas, visor TruView y videos divulgativos.

Los planos producto de los trabajos de digitalización corresponden a la planta y perfiles longitudinales más representativos. Presentamos a continuación alguno de estos ejemplos (Figs. 8, 9)

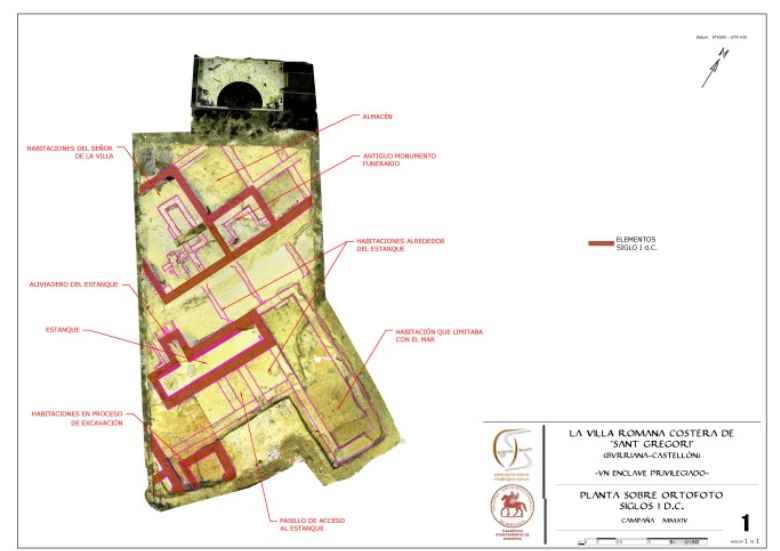

Figura 8: Plano de planta del sector excavado perteneciente al siglo I d.C.

Otro de los productos finales son las ortofotografías. Se trata de fotografías cenitales a escala sobre las que podemos realizar mediciones y observar los elementos en su verdadera magnitude (Fig. 10).

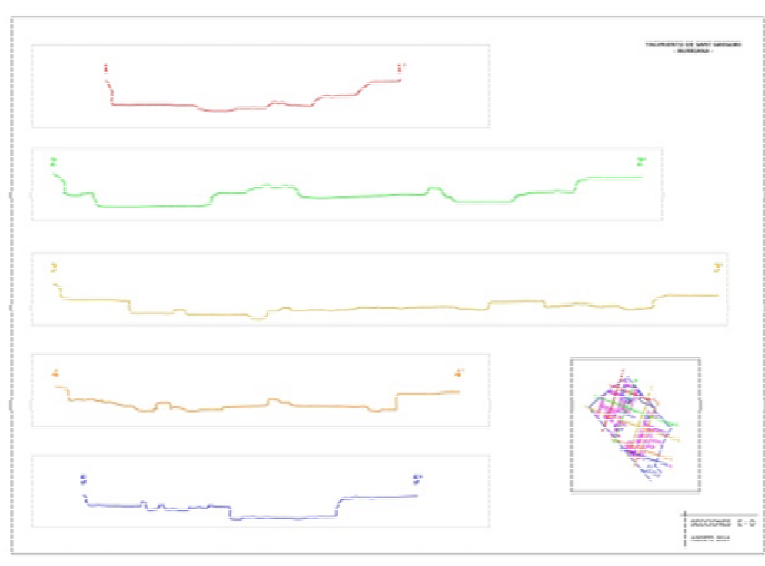

Figura 9: Plano de perfiles.

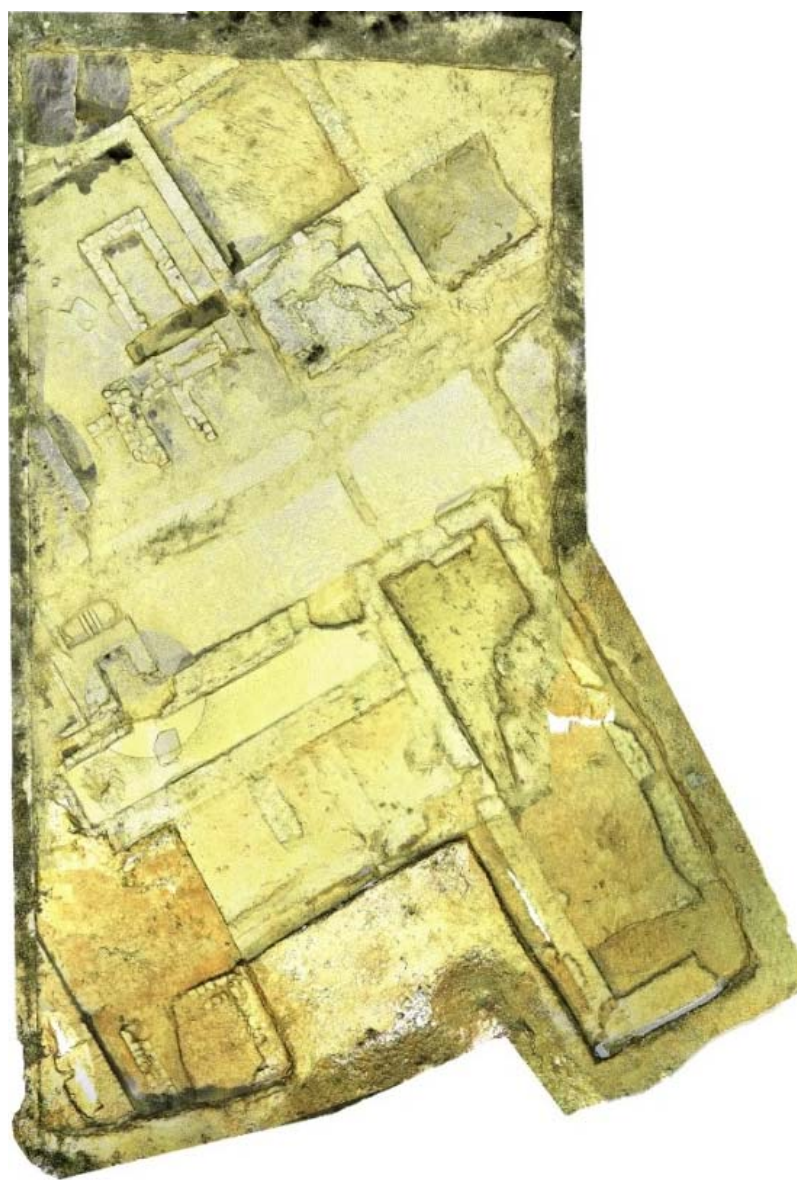

Figura 10: Ortofotografía del yacimiento.

Existe también la posibilidad de obtener ortofotos con las distintas visualizaciones (color verdadero, intensidades, color por estaciones, etc.), lo que nos permite resaltar ciertos aspectos de los objetos escaneados, apreciándose distintos detalles según la configuración elegida. El software utilizado en estos trabajos 'Cyclone' tiene una configuración particular llamada 'Silhouette' que resalta la concentración de puntos contenidos en el plano vertical. Esto es muy útil a la hora de estudiar e identificar elementos como muros y zanjas. Un ejemplo de esta visualización se puede observar en la siguiente Figura 11. 


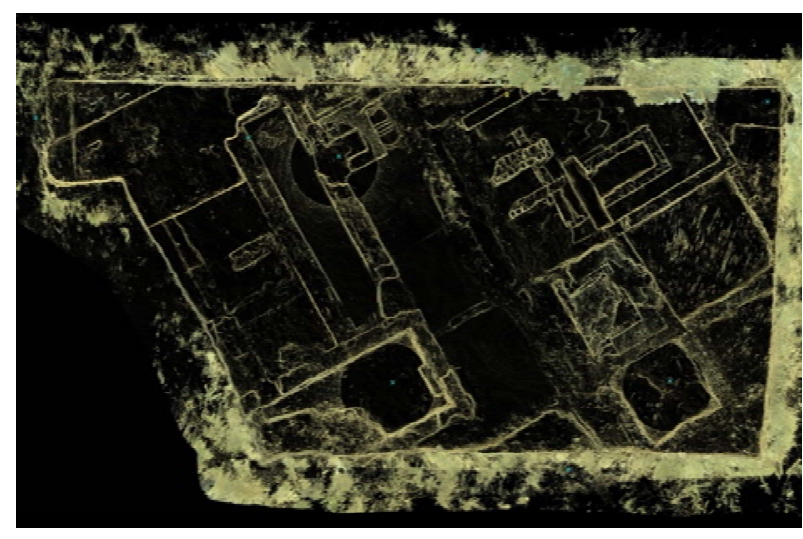

Figura 11: Visualización 'Silhouette'.

También son interesantes los distintos fotogramas extraídos de los detalles del yacimiento observados desde distintas perspectivas, que nos han ayudado a tener una mejor composición espacial del entorno (Figs. 12 y 13$)$.

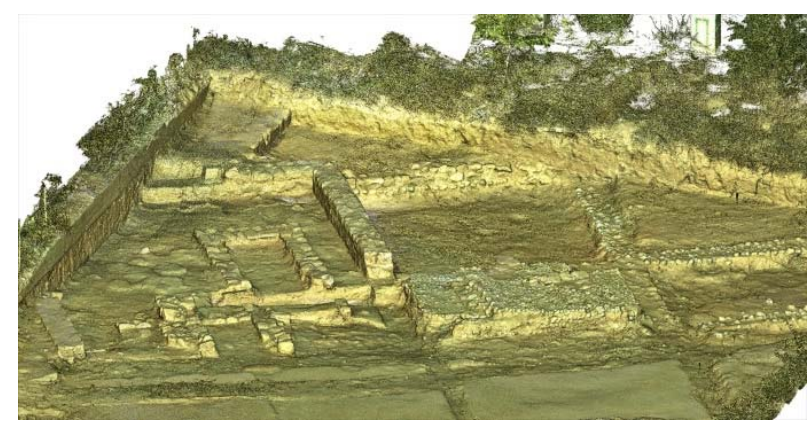

Figura 12: Nube de puntos.

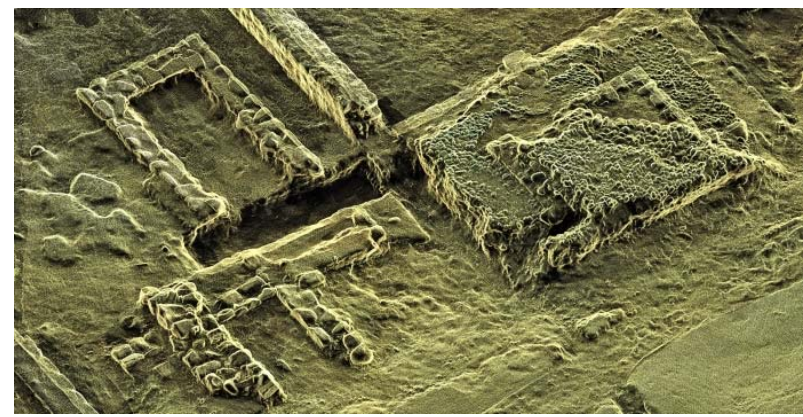

Figura 13: Nube de puntos en visualización 'Silhouette'.

Uno de los productos más interesantes para llevar a cabo el estudio arqueológico es el llamado 'TruView'. Se trata de un visor de los escaneados, el cual nos permite la observación del yacimiento desde el punto de vista del escáner. Al mismo tiempo que se visualizan los detalles, es posible realizar mediciones, anotaciones, extraer imágenes e incluso introducir enlaces a la documentación auxiliar (Figs. 14, 15 y 16).

Por último, en el marco de la documentación divulgativa, se llevó a cabo la edición de un video presentación del escaneado 3D del yacimiento de Sant Gregori en el que se muestran los resultados obtenidos.

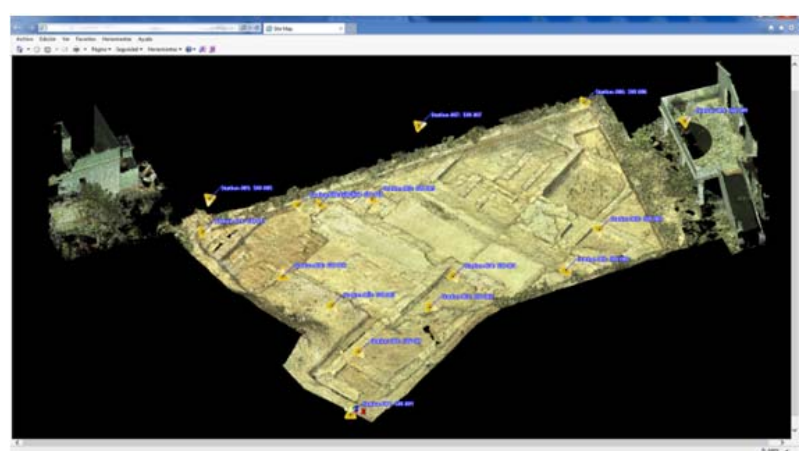

Figura 14: Pantalla de mapa de estaciones TruView.

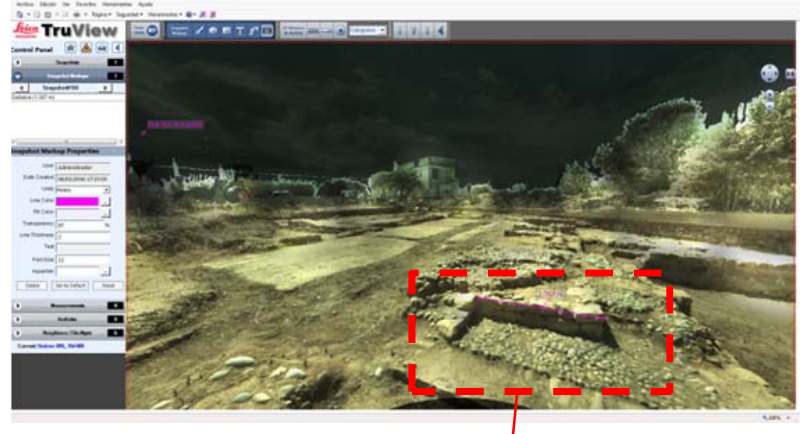

Figura 15: Vista de yacimiento desde estación en TruView.

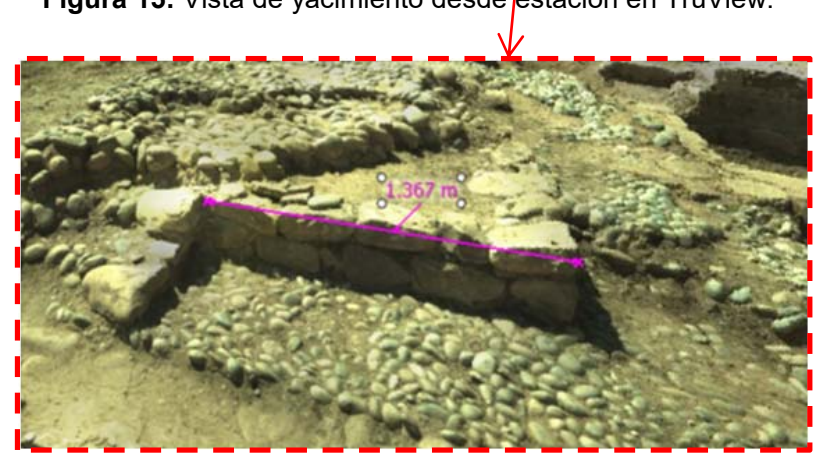

Figura 16: Detalle acotación de muro en TruView.

\section{Futuros trabajos a desarrollar: moldeado y SIG del yacimiento}

A partir de los resultados obtenidos en los trabajos de escaneado 3D, se ha planteado desarrollar nuevos productos.

\subsection{Modelado}

En el ámbito de la documentación divulgativa, se llevará a cabo el modelado virtual de la villa tomando como base la nube de puntos del escaneado. Estos trabajos requerirán la participación de un equipo técnico multidisciplinar. Con el estudio inicial del equipo arqueológico director del proyecto como base del trabajo y la colaboración de técnicos especialistas en gestión de datos de escaneado 3D, modelado virtual, texturización y ambientación, se recreará un escenario fidedigno de cómo eran las instalaciones de la villa romana en su época de esplendor.

Todo esto podrá ser culminado con la elaboración de una maqueta a escala que permita transmitir al público general las conclusiones de los trabajos arqueológicos 
realizados en la villa a lo largo de las distintas campañas de excavación.

\subsection{Modelado Sistema de Información Geográfica}

Debido a su potencial tanto científico como divulgativo, están en auge en los últimos tiempos los llamados Sistemas de Información Geográfica (SIG o GIS en inglés). Esta tecnología permite dotar de información adicional a la representación gráfica de cualquier elemento susceptible de ser grafiado, convirtiéndose así en una herramienta fundamental para el estudio del patrimonio cultural.

Se trata de una potente herramienta analítica que nos permite el estudio, catalogación, reconstrucción y análisis de toda la información recopilada desde cualquier tipo fuente, a la vez que nos posibilita la creación de documentación temática de gran valor divulgativo.

La elaboración de un SIG sobre el yacimiento de Sant Gregori, nos permitirá coordinar toda la información registrada hasta la fecha, ofreciendo la posibilidad de analizarla en todo su contexto, al igual que nos facilitará un mejor estudio sobre futuros trabajos arqueológicos.

\section{Tratamiento arqueológico de los resultados}

\subsection{Análisis cronológico del yacimiento}

Este artículo nos ha permitido poner sobre la mesa gran parte de las posibilidades que nos ofrece la documentación $3 \mathrm{D}$ que se ha realizado durante estas primeras cinco campañas de excavación en la villa romana de Sant Gregori (Burriana, España). A partir de este proyecto se nos abre también la posibilidad de aumentar la capacidad de investigación del yacimiento, contrastando los diferentes estados de conservación de los restos constructivos que se han registrado en la parte excavada y proyectar con ello la posterior restauración de los mismos (Fig. 17).

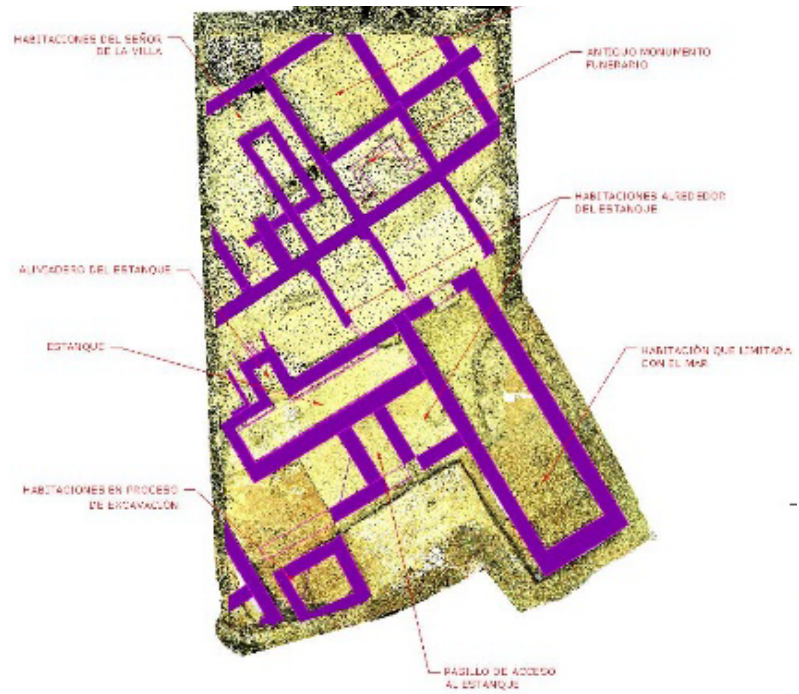

Figura 17: Plano del sector excavado perteneciente al siglo II.

La versatilidad de la herramienta 3D también nos ha permitido obtener planimetrías sincrónicas, por lo que refiere a usos y ambientes relacionados con las estructuras, y diacrónicas, que por otro lado reflejan las distintas etapas cronológicas que se sucedieron en el yacimiento.

\section{Referencias}

FERRER, J.J., MELCHOR, J.M. y BENEDITO, J., 2013. Sant Gregori. Un complejo arquitectónico de época romana en la costa de Burriana (España). Millars, XXXVI, pp.199-223. http://dx.doi.org/10.6035/Millars

FERRER, J.J., MELCHOR, J.M. y BENEDITO, J., 2014. El complejo arquitectónico de Sant Gregori en la costa de Burriana. Actas XVIII Congreso Internacional de Arqueología Clásica, J. M. ÁLVAREZ, T. NOGALES, I. RODÀ (eds.): Centre and periphery in the ancient world. Mérida, pp. 1143-1145.

MELCHOR, J.M., 2013. Diez años del Servicios Arqueológico Municipal de Burriana. Burriana.

MELCHOR, J.M. y BENEDITO, J., 2000. Campaña de excavaciones arqueológicas en los yacimientos de El Palau (Burriana, Castellón). Cuadernos de Prehistoria y Arqueología Castellonenses, 21. pp. 303-319.

MELCHOR, J.M. FERRER, J.J. y BENEDITO, J., 2014. Les excavacions arqueològiques en la vil·la romana de Sant Gregori: una porta oberta al coneixement de la badia de Borriana (Castelló) entre els segles I al IV. Quaderns dels Museus Municipals de València, 3, actuacions sobre el patrimoni arqueològic de la Comunitat Valenciana, actes de les I Jornades d'Arqueologia de la Comunitat Valenciana, pp. 101-112.

VERDEGAL, V., MESADO, N. y ARASA, F., 1990. Sant Gregori. Borriana, la Plana Baixa. Memòries Arqueològiques de la Comunitat Valenciana 1984-1988. Intervencions rurals. Generalitat Valenciana, pp. 115-117. 